Revista Iberoamericana, Vol. LXVIII, Núm. 201, Octubre-Diciembre 2002, 1025-1040

\title{
LA SUERTE QUE ES GRELA: TANGO, SEXO Y SOCIEDAD
}

POR

Abelardo Hernando

Georgetown University

Después de un largo proceso cuyos orígenes se remontan a mediados del siglo XIX, en la década de 1910 tienen lugar los últimos grandes cambios que producen lo que ha dado en llamarse la guardia nueva y que es lo que conocemos hoy como tango. Por un lado, el compás pasa de ser de 2 por 4 a ser de 4 por 8 , con lo cual se hace más lento, y por otro, nace el tango-canción. Los tangos de la guardia vieja en general no tenían letra, aunque a veces se les agregaba alguna de circunstancia y con carácter festivo. A partir de ahora, la letra, y la presencia del cantor, alcanzan prioridad sobre la danza. ${ }^{1}$ Hay al mismo tiempo una mayor profesionalización de autores, compositores e intérpretes que produce un verdadero progreso en la calidad musical del tango. En esta misma época el tango tiene un gran éxito en Europa, lo cual repercute en la misma Buenos Aires, donde está alcanzando gran popularidad merced primero a los organitos y posteriormente con los discos, la radio, los sainetes y el cine. Todos estos elementos producirán una verdadera explosión en la producción tanguera en las dos próximas décadas que no volverá a igualarse jamás; no por nada se la llama la época de oro del tango. Es aquí donde aparecen los tangos que marcarán no sólo esa época sino las generaciones siguientes, tangos que aún hoy siguen siendo favoritos. Es necesario remarcar que los cambios reseñados implican no sólo una cuestión formal o técnica sino también sociológica: el tango deja de ser la música del arrabal para transformarse en la música de la clase media. Aunque parezca una perogrullada, es necesario tener en cuenta que los autores de tango no son compadritos y rufianes sino poetas y músicos profesionales que producen para un mercado cada vez más grande. Este mercado está basado en el crecimiento y la transformación sufridos por la ciudad como resultado del flujo inmigratorio. Recordemos que en 1914 el 30 \% de la población del país y la mitad de la de la ciudad de Buenos Aires eran inmigrantes.

Este proceso dará lugar por un lado a la creación de una numerosa clase media y por otro al nacimiento de un lenguaje propio que será también el lenguaje del tango: el lunfardo. Este a su vez sufrirá también su propia transformación, de lenguaje secreto de los "lunfardos” (ladrones porteños) a lenguaje popular de Buenos Aires a través de la incorporación de vocablos y expresiones traídas por los “gringos” (inmigrantes europeos).

\footnotetext{
${ }^{1}$ Refiriéndose a Pascual Contursi, autor del que es considerado como el primer tango con letra argumental y de quien hablaré enseguida, Agustín Remón dijo que "era quien había llevado el tango de los pies a los labios” (citado por Horacio Ferrer y Luis Sierra, 67).
} 
El mayor símbolo de la unión entre tango e inmigración quizá esté dado por el hecho de que el mejor cantante en la historia del tango, y para muchos el prototipo del porteño, Carlos Gardel, había nacido en realidad en Francia. ${ }^{2}$

La etapa del tango-canción comienza en 1917 con la aparición del que es considerado en general como el primer tango con letra argumental: “Mi noche triste”, con letra de Pascual Contursi y música de Samuel Castriota. Carlos Gardel lo estrenó públicamente en el teatro Esmeralda de Buenos Aires y al año siguiente sería el primer disco grabado por Gardel. En este mismo año, 1918, aparece en el sainete Los dientes del perro y según Eduardo Romano, “[e]l enorme éxito de la obra se debió en gran parte a la inclusión de este tango, que se consagró así definitivamente” (32). Una de las cosas que vemos aquí es que ya para esta época el tango tenía un numeroso público con dinero suficiente para ir a los teatros, y a los cabarets, del centro. La que hasta hacía pocos años era considerada una danza maldita por la gente "bien” se transforma rápidamente en la música por excelencia de Buenos Aires.

Lo que resulta interesante es que esta gente se entusiasme por una canción que comienza diciendo: "Percanta que me amuraste / en lo mejor de mi vida” (Romano 30). Es la introducción no sólo de un nuevo ritmo musical sino también de un lenguaje y de una forma de ver a la mujer y a la relación de pareja. Al contrario de la posición machista clásica, que sería dable esperar en esta circunstancia, la voz poética masculina en este tango llora porque la mujer que ama lo ha dejado, lo que abrirá una larga tradición dentro del tango. La descripción de los elementos materiales del "cotorro" (habitación, departamento, casa) simples, casi pobres, destaca la ausencia de la mujer y enmarca la tristeza del hombre, llegando incluso a la personificación de la "catrera" (cama) que se enoja porque no los ve a los dos y de la lámpara que, notando la ausencia de la mujer, se niega a dar su luz. La imagen que se crea con esta descripción es de felicidad conyugal (poco importa si estaban realmente casados o no) rota por la partida de la mujer. Pero lo más interesante es la ausencia total de bravuconadas y de recriminación hacia ella, aunque esto vendrá con tangos posteriores. Tampoco se menciona por qué se fue. El tema es exclusivamente el amor y el dolor del hombre (enfatizado en el título), lo que es realzado por la escenificación presentada como, asimismo, por el registro varonil de la voz poética, en el que el uso del lunfardo ocupa un papel fundamental.

Recordemos que estamos en los primeros años del gobierno de Hipólito Yrigoyen, primer presidente elegido con el voto popular. La clase media está en ascenso frente a la oligarquía que ha dado un paso al costado y mira con desconfianza. Es esta clase media, precisamente, la que, según Eduardo Romano, “necesita convencerse de que la capacidad sentimental es un atributo más confiable que el nombre y los bienes heredados o acumulados" (8). No sólo es de hombre sentir el amor sino también ser capaz de expresar los sentimientos. Pero éste parece ser en realidad un atributo sólo de las clases populares. En el párrafo anterior enfatizaba la importancia de la descripción de la pobreza del “cotorro”. En “Muchacho”, en cambio, de Celedonio Flores, aparecido en 1924, se nos

\footnotetext{
${ }^{2}$ El lugar de nacimiento de Gardel es objeto de polémica. Su carácter de inmigrante, sin embargo, creo que está fuera de toda duda al margen del accidente del lugar específico donde haya sido dado a luz.
} 
cuenta de un joven rico que vive en un "palacete central” y la crítica fundamental es que si tiene sentimiento, lo tiene adormecido "pues todo lo has conseguido / pagando como un chabón" (Romano 71). Aquí se establece una diferencia fundamental: sentimientos versus dinero; puede comprar mujeres (como un chabón: tonto) pero no sabe "el encanto / de haber derramado llanto / por un amor de mujer”. Frente a los “vicios y placeres” y las "farras y mujeres" a que está acostumbrado el muchacho rico, se oponen la dicha de haberle "dicho a una pebeta / que ella es más linda que el sol” o la belleza de una tarde de arrabal, "cuando van las fabriqueras / tentadoras y diqueras / bajo el sonoro percal”.

El percal, tela barata de algodón, adquiere en el tango un valor metonímico simbólico de pobreza, pero pobreza honrada. Lo vemos en el último verso citado e incluso hay un tango que lleva el título de "Percal”. Abandonar las ropas de percal implica desclasarse, traicionar a la clase de origen, dejarse engañar por la ilusión del dinero y el lujo. Es lo que vemos, por ejemplo, en "Margot", del mismo Celedonio Flores. Aparecido dos años después que "Mi noche triste”, y a diferencia de éste, en "Margot” la voz masculina es de reproche a la mujer pero, curiosamente, no tanto por haberlo dejado sino por haberse "abacanado". Y una de las consecuencias de su abacanamiento es precisamente que su cuerpo "acostumbrado a las pilchas de percal” ahora usa "ajuar de seda con rositas rococó" (Romano 34). Este último marca, irónicamente, la magnitud de su caída.

$\mathrm{Y}$ digo irónicamente porque el supuesto triunfo de la mujer al abandonar el conventillo de arrabal y llegar a los lugares de diversión de la gente bien que menciona el tango, como el Armenonvil, el Petit o el Julien, se ha dado a través de su velada, o no tan velada, prostitución. Este tango, y tantos otros con el mismo tema que aparecen en esta época, apunta a un problema central: el crecimiento de Buenos Aires con la inmigración y un incipiente desarrollo industrial producen no sólo el crecimiento de la clase media por un lado, sino también tremenda miseria en los arrabales por otro. Familias enteras viven hacinadas en lo que se dio en llamar conventillos y el trabajo honesto no siempre garantiza el mantenimiento de la familia. Al mismo tiempo, Buenos Aires es un centro mundial de la trata de blancas y los prostíbulos no serán prohibidos hasta la década de 1930. Quizá una de las razones que expliquen el éxito de los burdeles esté dado por el hecho de que había muchos más hombres que mujeres, dado que muchos inmigrantes venían solos con la ilusión de juntar algún dinero ("hacerse la América”) y luego traer a sus familias o incluso volver definitivamente a sus tierras de origen. El prostíbulo era lugar no sólo de satisfacción de las necesidades sexuales sino también de socialización, y de ahí el papel que le cupo en el desarrollo del tango. Refiriéndose a la producción tanguera de esta época, Eduardo Romano sugiere que

Puede ser leída como eminentemente conservadora, porque recomienda un repliegue en el hogar, sobrevalora el cariño materno y privilegia la fusión con el barrio; pero, en realidad, intentaba preservar a la familia modesta en circunstancias sociales adversas: los patoteros y otros gavilanes seducían a las muchachas de barrio para convertirlas luego en sus queridas y alegrar las garçonniers con todo lo que las sanciones represivas de la época condenaban, sin olvidarnos de las asociaciones delictivas que estaban permanentemente a la caza de pupilas y que empleaban diversos señuelos para lograrlo. (11) 
La defensa de la familia pasaría entonces, como siempre, por la defensa del que es supuestamente su eslabón más débil: la mujer. Y la defensa de la familia, y del barrio como señala Romano, es en último término una defensa de clase. Los patoteros, cuya imagen actualmente se asocia automáticamente con elementos de baja condición social, eran por el contrario en aquel momento, cuando surgió la denominación, grupos de jóvenes ricos que cometían toda clase de tropelías amparados en el número y, si las cosas pasaban a mayores con la policía, en las conexiones e influencias propias de su clase. Sin embargo, creo que la cuestión no es tan simple. Es importante tener en cuenta que la abrumadora mayoría de autores de tango, particularmente en esta época, son varones, con lo cual lo que tenemos es una visión exclusivamente masculina. Si bien los peligros, como mencioné en el párrafo anterior, eran reales, la imagen de "gavilanes" presenta a las mujeres, por oposición, como víctimas indefensas sin ningún poder de decisión. Sin embargo, como ya hemos empezado a ver con "Margot" — y llama la atención la cantidad de tangos con este tema - la preocupación central parece ser la agencia de la mujer. En este sentido, quizá deberíamos revalorizar lo expresado por Romano en el sentido de que el repliegue en el hogar y la sobrevaloración de la figura materna son realmente actitudes conservadoras que apuntan a mantener el lugar tradicional de la mujer mientras que ésta, poco a poco, tiende a abandonarlo. Lo que vemos entonces es el surgimiento de un nuevo discurso producto del cruce de posiciones contradictorias de clase social y de género sexual. Es por eso que la voz masculina en "Margot" se esfuerza en aclarar que "no fue un guapo haragán ni prepotente, / ni un cafishio de averías el que al vicio te largó; / vos rodaste por tu culpa, y no fue inocentemente: / ¡berretines de bacana que tenías en la mente / desde el día en que un magnate cajetilla te afiló!” (Romano 34). Lo que se critica entonces es el poder de decisión de la mujer que, en este caso, prefiere ser la amante de un magnate en lugar de continuar en la miseria. El tango cierra con la comparación en la última estrofa de Margot, que decidió irse, con su madre, que se quedó en el conventillo aceptando el papel tradicional de la mujer. El haberse ido le permite a Margot comer en un "lujoso reservado" de un restaurante de moda, pero el lujo está calificado por tener lugar precisamente en un reservado, implicando que el precio de ese lujo es su “virtud”. Su madre, por el contrario, come con “pobreza franciscana”, es decir honesta, basada en su trabajo de lavar ropa todos los días. La falta de Margot es por lo tanto múltiple: abacanarse, abandonar su casa y su barrio, perder la virtud, abandonar a su propia madre e incluso abandonar la posibilidad de ser madre ella misma en el futuro, con lo cual, según el discurso dominante de la época, deja de ser verdaderamente mujer para transformarse en monstruo (véase Amadeo, La función social).

Junto al tema de "la mina que se piantó del bulín” tenemos también las supuestas consecuencias de tal accionar. Un gran número de tangos están construidos sobre la idea de que la belleza y la juventud de la mujer, únicos elementos que le permiten irse, son efímeros y por lo tanto el fin inevitable para la mujer es el abandono, la enfermedad y la pobreza. Es lo que ocurre por ejemplo en "Flor de fango" (1917) y en "El motivo" (1920) de Pascual Contursi, autor, como hemos visto, de "Mi noche triste”. En el primero de estos tangos, la mujer abandona a los catorce años el "conventillo / alumbrao a querosén” porque obviamente le "gustaban las alhajas / los vestidos a la moda / y las farras de champán” (Romano 32). El tango cuenta la parábola de esta mujer que arruinó a varios hombres hasta 
que uno, “el hijo de un comisario”, le quitó todo el dinero y ahí empezó su decadencia, no teniendo "ni un cariño ni un consuelo" porque, y esto es lo peor, "el amor de [s]u madre [1]e faltó”. En “El motivo”, la “mina que fue en otro tiempo / la más papa milonguera / y en esas noches tangueras fue la reina del festín ... / Hoy no tiene pa’ ponerse / ni zapatos ni vestidos, / anda enferma, y el amigo / no aportó para el bulín” (Romano 37). Continuando con la estructura planteada en éstos, los primeros versos, este tango funciona en base a la oposición en cada estrofa entre lo que fue su belleza y su popularidad en el pasado y la soledad y tristeza del presente, sufrimiento que se acentúa porque sabe perfectamente "de que así, enferma y sin vento, / más naides la va a querer" ("vento": dinero). Lo que ocurre aquí es muy interesante porque en el proceso de narrar el ejercicio de la agencia por parte de la mujer, ésta es en realidad se torna objeto; es decir, la mujer es representada específicamente como un objeto en ambos sentidos: de deseo y como cosa, que al envejecer o enfermarse (y no tener dinero propio) pierde su valor de uso. Esta reificación de la mujer alcanza uno de sus puntos culminantes en "Mano a mano" (1920) de Celedonio Flores, en donde la voz masculina pronostica que la mujer se convertirá inevitablemente en "descolado mueble viejo" (Romano 39).

Los españoles se refieren al tango como “el lamento del cabrón”. En la misma tesitura, José Gobello sostiene que

De Contursi a hoy, el lamento del amante abandonado encierra, en el tango, la condenación de la infidelidad. Cuando el protagonista del tango perdona a la infiel, más que un agravio [...] está perdonando un pecado. Cuando hiere y mata, no lo hace por desquite ni por despecho sino con ánimo justiciero. La fidelidad, la lealtad es cronológicamente el primero de los valores éticos que el tango canción rescata y exalta. (La historia del tango 900)

Sin embargo, como hemos visto, la representación de la mujer en el tango de esta época no es la de alguien que engaña sino que se va abiertamente. Esta distinción me parece importante porque el cornudo está tradicionalmente asociado con el marido engañado. Lo que vemos abrumadoramente en realidad no es tanto adulterio, si quisiéramos ponerlo en términos jurídicos, sino divorcio. Es decir, el objetivo no es engañar al hombre sino romper definitivamente con él, pero claro, teniendo en cuenta que en esa época, y por muchos años más, el divorcio no sería legal en Argentina. Esto es también complicado por el hecho de que, como hemos visto en "Flor de fango", "El motivo” y otros tangos, la crítica a la mujer no es sólo por dejar a su hombre sino en general por romper con los cánones tradicionales asignados a la mujer y construirse, como lo simboliza el cambio de nombre de Margarita a Margot en el tango con este último título, una nueva personalidad. El tango reacciona entonces desde un punto de vista masculino amenazado por el comienzo de un cambio en los roles tanto del hombre como de la mujer. En este sentido, el compadrito y la milonguita funcionan paradigmáticamente, el uno como representante del valor, y el estoicismo si se quiere, masculino y la otra como símbolo de la mujer que se pierde por no aceptar su papel doméstico. Como ocurre con la idealización de la figura del gaucho cuando éste en realidad ya no existe más, el compadrito también ha pasado a la historia en esta época y su permanencia en el tango tiene un indudable carácter nostálgico por un 
pasado donde los comportamientos sexuales estaban más fijos y no en flujo como ahora. De la misma manera, no todas las mujeres que abandonaban el espacio doméstico, paterno o conyugal, lo hacían para transformarse en milonguitas. Como sostiene Eduardo Archetti, el cabaret era un espacio real pero al mismo tiempo, y aun más importante, un escenario de ficción para imaginar historias que servía, metafóricamente, como una imagen poderosa en contraste con el hogar y el barrio (139). La figura de la milonguita en realidad sirve para castigar a la mujer en el tango, como hemos visto, reificándola.

Gobello se hace eco de una ética católica donde el amor se supone eterno y la infidelidad aparece como pecado. No se concibe que el amor pueda terminar, por lo tanto se considera que la mujer que se va ha engañado retroactivamente al haber dicho que amaba. Al dar su palabra, la mujer se transforma en propiedad (objeto) sin ningún poder de decisión. Esto plantea a su turno la supuesta superioridad moral del hombre sobre la mujer: ella es "la” infiel, él es el que perdona. Esta actitud está muy clara en, por ejemplo, "Mano a mano" donde la voz poética "perdonavidas" se ofrece al final a "jugarse el pellejo” si es necesario para ayudar a la mujer que lo dejó. Cuando ella sea "descolado mueble viejo”, él será el único “amigo” con quien pueda contar (Romano 39). Gobello llega a justificar la otra actitud, el castigo, incluso herir y matar, “con ánimo justiciero”. Si hacía falta alguna prueba de la supervivencia de los valores que el tango "rescata y exalta”, y también de su carácter nostálgico, recordemos que todo esto Gobello lo sostiene en 1977.

"El patotero sentimental” (1922) es de alguna manera la contrapartida de los tangos de los que he estado hablando. Aquí el patotero del título recuerda a la "fiel mujer" que lo "quiso de verdad” y que él abandonó. Ante el llanto de ella, él debe resistir porque "la patota me miraba / y no es de hombre el aflojar” (Romano 48). Su comportamiento está determinado por su pertenencia al grupo, y su subjetividad masculina no es libre sino acotada por reglas impuestas por ese mismo grupo. En una imagen semejante a la milonguita que ríe para ocultar su llanto al salir del cabaret, la risa del patotero "sólo es ganas de llorar”. Esta última idea ya se plantea en la primera estrofa pero en la última el llanto es la imagen central y se desliza desde la mujer al principio hacia el hombre al final. El llanto en ambos casos está producido por la misma acción, la acción del hombre, pero en el caso de éste último indica arrepentimiento y por lo tanto lo transforma en víctima. Eduardo Romano cita a Francisco García Jiménez, quien en Así nacieron los tangos dice que en este tango, su autor Manuel Romero logró

convertir la imagen bárbara del patotero en la menos dura de un ‘seductor’ desaprensivo. Contó para ello con la emotividad y convicción puestas por Corsini [el cantante] al servicio de la letra, lo que hizo que en el primer bis, el patotero (unido siempre a 'crónicas policiales') fuera ya un conmovedor amante atormentado ganándose la adhesión de la sala entera. (49)

Es interesante ver que la imagen de seductor desaprensivo sea considerada menos dura que la de patotero. Pero claro, lo de patotero sentimental de todas maneras es un oximoron que se resuelve en favor de la imagen de un conmovedor amante atormentado. Su sufrimiento, su capacidad de darse cuenta que se ha equivocado y, por supuesto, sus lágrimas tienden a ganarse la simpatía de la audiencia —recuérdese lo ya dicho sobre la 
capacidad de expresar sentimientos. Pero este proceso implica por un lado ignorar la victimización de la mujer en primer lugar y por otro relativizar la importancia de la fidelidad a que hacía referencia José Gobello.

Que la nueva libertad de la mujer es la preocupación central del tango de esta época aparece meridianamente claro en "Amores viejos" (circa 1920) del mismo Pascual Contursi, quien popularizara el tema de la mujer que se va, como hemos visto. En este tango la voz masculina específicamente compara las mujeres actuales con las de antes y se compadece de que frente a "esas minas veteranas / que nunca la protestaban; / sin morfar se conformaban / aunque picara el buyón” (se conformaban sin comer aunque tuvieran hambre), las mujeres "hoy sólo quieren vestidos / ríquisimas alhajas / coches de capota baja / pa’ pasiar por la ciudad” (citado por Noemí Ulla, 86). Por un lado se idealiza la mujer abnegada que nunca protesta ni pide nada, es decir que sabe "mantener su lugar", como la madre que lavaba ropa en el conventillo, mientras por otro se descalifica a las mujeres que desean la independencia al sugerir que lo hacen simplemente por motivos materialistas y egoístas. El mismo Contursi lleva esta actitud de crítica en forma de burla en el tango humorístico "La mina del Ford” donde la mujer del título, "aburrida / de aguantar la vida" que el hombre le dio, “cachó el baúl una noche y se fue cantando” que quería vivir en el lujo (Romano 72-73).

Un ejemplo de mujer abnegada, dispuesta a perdonar al hombre que la dejó si vuelve con ella es la voz poética en “Julián” (1923). Esta le dice: “yo nunca podré olvidarte / y siempre sabré esperarte. / Piensa en el nido abandonado, / un corazón destrozado / sólo puede perdonar” (Romano 54). Esto último es particularmente interesante puesto que plantea para la mujer el perdón como única alternativa, y esto a su vez está directamente relacionado con la necesidad de reconstruir el hogar abandonado por el hombre. A diferencia de las motivaciones que aparecen en los tangos que hemos visto para que las mujeres se vayan, el hombre en este caso no se va en busca de mejoras económicas sino tras otra mujer, lo que lo coloca en un plano moral superior a aquéllas; no se va tras el vil dinero sino "entusiasmado / por una loca ilusión”, y es por lo tanto comprensible, redimible y perdonable. En este mismo año aparece otro tango, “Padre nuestro”, exactamente con el mismo tema y en el cual la voz femenina implora a Dios por el regreso del hombre que se fue. Lo más interesante es que aunque en ambos casos la voz poética es femenina, los dos tangos fueron en realidad escritos por hombres, José Luis Panizza y Alberto Vacarezza respectivamente, y resulta imposible no verlos como una expresión de deseos masculinos y como parte de un discurso que intenta reconstruir un modelo de mujer que se percibe como comenzando a resquebrajarse.

“Príncipe” (1924), de Francisco García Jiménez, es altamente sugestivo en este sentido. La voz poética masculina recuerda la felicidad doméstica que disfrutó en el pasado hasta la muerte de su esposa pero se refiere a ella como una excepción. Por un lado dice que "Lo que perdí no he de encontrar otra vez" y por otro lado sostiene que "cuando les digo que he sido un príncipe, / los desalmados lo echan a risa” y lo llaman "loco" (Romano 67). Termina el tango reafirmando que "no soñé / Príncipe fui, tuve un hogar y un amor”. El propio título del tango y con el que se refiere a sí mismo remarca esta calidad excepcional de tener "un hogar y un amor".

La figura de la madre, como ya hemos visto, juega un papel fundamental en la defensa de la domesticidad y del modelo tradicional de mujer, con lo cual está directamente 
relacionada la felicidad del hombre. En "Nunca es tarde” (1924) de Celedonio Flores, la voz poética critica al hombre porque "Vos dejaste los encantos de un bulín donde tenías / una madre viejecita y una hermana que cuidar, / un bulín donde vos eras esperanza y alegría / por seguir a esa malvada que te acaba de amurar” (Romano 70). La mujer encarna los peores estereotipos femeninos que a través de la historia, desde Eva, seducen al hombre y lo llevan a la perdición. El bulín del que se fue, por otra parte, con la presencia de la madre y de la hermana, es el espacio donde residen los “deberes" y los "encantos" del hombre. Por eso es que al final de este tango es posible restituir el equilibrio perdido: “Andá a verla a tu viejita, dale un beso y un abrazo/y llorando preguntale si te quiere perdonar”. El hombre, indefenso ante la mujer, sólo puede encontrar refugio como eterno niño en el seno materno. El mismo autor insiste con este tema en un tango con el muy sugestivo título de “Tengo miedo" (1920). Aquí la voz poética se dirige específicamente a una mujer diciéndole que ha decidido abandonar una vida que lo llevaba a la "ruina sin remedio", entre otras cosas "cariños pasajeros, besos falsos de mujer”, y todo lo deja "por el cariño más santo que un hombre puede tener” (Romano 106). El problema con la mujer en este caso, a diferencia de los tangos de Pascual Contursi, no es que se va sino que puede volver, no aparece como pérdida sino como amenaza. Por eso es que el hombre le suplica que no venga a "turbar mi dulce paz, / que me dejes con mi madre, que a su lado santamente / edificaré otra vida ya que me siento capaz”. El hogar materno aparece como un idealizado espacio doméstico, el único posible frente a la incapacidad de formar una pareja con la mujer asociada a la perdición. La madre es la única mujer que puede amar incondicionalmente y frente a esta vara de medición, toda otra mujer es deficiente.

Durante mucho tiempo se seguirían haciendo tangos con estas características. La fórmula introducida por Pascual Contursi en 1917 con "Mi noche triste" sería copiada hasta el hastío por el mismo Contursi y sus seguidores. Pero en 1926, el mismo año en que aparece el tango de Celedonio Flores recién analizado como así también "La he visto con otro” y "Pobre corazón mío” de Contursi, “Tus besos fueron míos” de Francisco García Jiménez, "El abrojito” de Jesús Fernández Blanco y otros que continúan llorando a la mujer que se fue, aparece “Quevachaché” de Enrique Santos Discépolo.

En el momento de su aparición este tango fue decididamente rechazado por el público. Según el mismo Discépolo,

era algo distinto. No digo que mejor ni peor. Digo que era distinto de todo lo que se había escuchado hasta entonces como tango. Decía otras cosas, enfocaba la vida de otro modo. Miraba por otras ventanas el tremendo panorama de la humanidad. Con ese tango comenzaba una producción en la cual iban a tener cabida otras formas de expresión. Se iban a abordar temas que no habían sido encarados por otros tangos. No juzgo aquí calidad, sino tema, asunto, forma de realización. (Ferrer 40)

No sería hasta algún tiempo después, particularmente a partir de la crisis del 30, que éste y otros tangos de este autor no sólo serían aceptados sino que lo transformarían en uno de los grandes poetas del tango. ${ }^{3}$

\footnotetext{
${ }^{3}$ Vale la pena recordar que en este mismo año, 1926, aparece la primera novela de Roberto Arlt, $E l$ juguete rabioso, y que ambos, Discépolo y Arlt, tendrían mucho éxito en la década siguiente, la que pasaría a la historia de los argentinos con el nombre de "década infame".
} 
“Quevachaché” comienza rompiendo con el estereotipo de mujer creado por el tango hasta ese momento por cuanto que no es ella la que se va sino que, por el contrario, ella echa al hombre porque está cansada de pasar hambre. En el transcurso del tango, enrostra al hombre su honradez y su decencia y su ilusión de cambiar al mundo. Ella sostiene que “el verdadero amor se ahogó en la sopa / la panza es reina y el dinero Dios” (Romano 104). Domingo Casadevall afirma que este tango "lleva a la cúspide la cínica estimativa del bajo Buenos Aires, cantada por la ciudad entera [...] La crítica consideró esa composición como una instigación a la mala vida”, mientras que Tomás de Lara e Inés Leonilda Roncetti de Panti dicen con respecto al autor que "Muchas veces se duda si no está incitando a las bajas pasiones del pueblo” (Noemí Ulla 111-112). El énfasis de estos críticos en "bajo Buenos Aires”, "mala vida” y "bajas pasiones" parece presentar la imagen de una sociedad inmaculada sobre la cual se cierne un peligro que proviene de las clases bajas y que estaría representado e incentivado por el tango de Discépolo. La última cita continúa diciendo que "Es evidente que ha tenido influencia poderosa sobre éste [el pueblo] y que su prédica negativa ha coincidido con el rebajamiento moral de las últimas décadas” (112). Sin embargo, lo que hace "Quevachaché" es apuntar a un estado generalizado de corrupción en la sociedad donde "la razón la tiene el de más guita [...] la honradez la venden al contado / y a la moral la dan por moneditas” (Romano 104). A estos críticos se les escapa por completo la ironía en estos versos y terminan poniendo el carro enfrente del caballo. Lejos de incitar a las bajas pasiones, son en realidad una denuncia. Como dice Norberto Galasso con respecto a este tango, "Esos versos son uno de los escasos testimonios que refutan la fábula rococó con que se hace el panegírico de la presidencia de Alvear” (48). El hecho de ser uno de los primeros testimonios de una crisis generalizada y que, en este sentido, rompe con cierta idealización de la pobreza existente en la tanguística anterior, explicaría la recepción que tuvo originalmente por parte de una clase media que no estaba acostumbrada a que se le enrostrara su hipocresía y a que se le desnudaran sus valores morales. ${ }^{4}$ Hablo de una idealización de la pobreza porque, como hemos visto, el sujeto masculino construido por los tangos anteriores se siente superior moralmente a la mujer porque, a diferencia de ésta, no se deja arrastrar por la atracción del dinero y el lujo. El se queda solo y pobre en el cotorro mientras la mujer escapa tras una ilusión, sintiéndose ésta después culpable y triste. Por supuesto, este sentimiento de culpabilidad y tristeza, aunque tardío, le da la razón al hombre. En “Quevachaché” por el contrario, la ilusión está en el hombre, que resulta, "haciendo el moralista, / un disfrazao...sin carnaval” (Romano 104). Antes la mujer era una "caída" que atentaba contra un orden social sostenido sobre valores morales conservadores. Ahora se muestra a ese orden social en general como inmoral y corrupto. “Quevachaché” desnuda la hipocresía de la sociedad burguesa, y sostiene que el que se toma en serio sus reglas es un "gilito embanderado” (gilito: tonto). Aunque, claro,

\footnotetext{
${ }^{4}$ Con respecto a Casadevall y a Lara y Roncetti de Panti, es un poco más difícil entender su posición ya que el primero escribe en 1957 y los otros dos en 1961, lo que supuestamente les daría cierta perspectiva histórica con la cual analizar el conjunto de la obra de Discépolo. Noemí Ulla sugiere que el "rebajamiento moral de las últimas décadas" podría referirse al peronismo. La crítica de estos autores a Discépolo, entonces, estaría relacionada con la conocida adhesión de éste a ese movimiento político.
} 
es importante tener en cuenta, de todas maneras, que el "gilito" que se aferra a valores morales es el hombre y la "realista" es la mujer.

La tanguística de Discépolo tiene como antecedentes su formación en el teatro junto a su hermano Armando en la creación de lo que se dio en llamar el "grotesco criollo" bajo la influencia de autores italianos, especialmente Pirandello. El mismo Discépolo sostiene: "Yo tengo algunos tangos de forma cómica, pero de fondo serio. Son de ese género que hemos convenido en llamar grotesco" (Ferrer, 105). ${ }^{5}$ Uno de estos tangos grotescos es “Chorra”, aparecido en 1928, en el que el uso del lunfardo es uno de los elementos cómicos, comenzando por el título (que significa "ladrona”). La voz poética masculina increpa a la mujer por haberle robado, pero no sólo los elementos materiales, como "el mercadito, / la casiya de la feria, la ganchera, el mostrador”, es decir los medios de subsistencia, sino también "hasta el amor" (Romano 149), y esto es lo más grave, claro, porque el fraude material es posibilitado solamente por el engaño sentimental. Pero el hombre dice que "Lo que más bronca me da, / es haber sido tan gil” mientras que al comienzo del tango plantea que la mujer lo puso en la miseria "por ser bueno". Es decir que el engaño de la mujer está basado en esta equivalencia entre la bondad y la estupidez del hombre, y ésta última a su vez está dada por ignorar la naturaleza femenina: debería haber sabido que la mujer es un animal de presa.

La "forma cómica" de este tango, y la característica grotesca, proviene fundamentalmente del contraste brutal entre la historia que ella le contó al hombre y la realidad. Según ese cuento, la mujer era hija de la "noble viuda de un guerrero / [...] / que murió lleno de honor”. Esta mentira no sólo encubre la verdadera identidad de la mujer sino que además juega explícitamente con las pretensiones pequeñoburguesas del hombre. El engaño de éste es doble entonces: pierde no sólo el amor de la mujer sino también su ilusión de ascenso social. El lenguage mismo utilizado, como señalaba antes, agrega a ese efecto cómico al establecer la posición social del hablante y hacer aquella ilusión aun más ridícula. Porque efectivamente, la madre de la mujer en realidad “es la chorra de más fama / que ha pisao la treinta y tres” (en referencia a la comisaría 33 de la policía), mientras que el padre no sólo no murió sino que “está en cana prontuariado / como agente 'e la camorra, / profesor de cachiporra, / malandrín y estafador”. Pero esta forma cómica, como veíamos antes, encierra un fondo serio, según el mismo Discépolo, y éste es el "desayunarse” (epifanía en el sentido joyceano) del carácter depredador de la sociedad y en particular de la mujer. Toda la familia le robó, pero fue la "silueta" de ella y sus "rebusques de mujer" los que hicieron que cayera en la trampa. Por eso, ahora "tanto me asusta una mina / que si en la calle me afila/ me pongo al lao del botón” (si una mujer lo corteja en la calle, se pone al lado de un policía).

La domesticidad burguesa es para Discépolo una jaula donde el hombre pierde su libertad y hasta su hombría. En "Malevaje” (1928), el que fue guapo ha sido convertido por la mujer en un cobarde. Tradicionalmente la mujer ha debido adaptarse al hombre pero aquí vemos cómo la acción de la mujer ha transformado radicalmente la subjetividad del

\footnotetext{
${ }^{5}$ La historiografía oficial considera a Armando Discépolo como el creador del grotesco criollo y a su hermano Enrique como un simple colaborador. Norberto Galasso considera que esta relación debe en realidad invertirse. Ver el apéndice A de su libro, páginas 195-7.
} 
hombre, quien comienza y termina el tango diciendo: “¡Decí por Dios qué me has dao / que estoy tan cambiao / no sé más quién soy!” (Romano 151). El hombre siente que ha dejado de ser sujeto para convertirse en objeto (de los designios femeninos). Una lectura femenina, claro, ofrecería una diferente valoración donde el énfasis estaría precisamente en la construcción de una subjetividad femenina capaz de “domesticar” al malevo más feroz.

Horacio Ferrer y Luis Adolfo Sierra sugieren que

“Malevaje” es la palinodia del malevo. La transfiguración del “machismo” tanguero. Termina Discepolín con el mito anacrónico del Juan Moreyra en el tango. Ridiculiza por boca del propio protagonista, los atributos de una hombría convencional teatralmente atribuida a una suerte de matón que nada tiene ya que ver con nuestra realidad social.

Esto último es clave y reitera lo que ya habíamos señalado con respecto al compadrito. Como los mismos Ferrer y Sierra afirman inmediatamente antes de la cita anterior, “en los tangos de Discépolo no hay malevos, ni guapos. Su mundo social reside en el hombre de la clase media. Los problemas que presenta son de indudable extracción burguesa” (11213). Lo importante entonces es ver cómo funciona la figura del malevo para la clase media. Si Don Quijote tiene más que ver con la construcción de la subjetividad que con la desmitificación de las novelas de caballería, “Malevaje” tiene más que ver con un sujeto masculino que se siente amenazado por el ascenso de la subjetividad femenina que con un mito que ha pasado a la historia. Aunque quizá, después de todo, estas oposiciones no sean del todo correctas porque el sujeto quijotesco se construye, al menos en parte, en oposición precisamente al sujeto de la novela de caballería, es decir al sujeto ideal, es decir ideológico, de un período histórico anterior. De la misma manera, el proyecto discepoliano textualiza una subjetividad masculina conflictuada, entre otras cosas, por el ascenso de la subjetividad femenina y la pérdida de valores que parecían inmutables.

Es esta visión masculina de la mujer y del efecto de la domesticidad sobre el hombre lo que textualiza "Victoria” (1929). En directa contraposición a los tangos tradicionales que hemos visto en los cuales la voz masculina lloraba la partida de la mujer, en este tango cómico el hombre clama “¡Victoria! / ¡Cantemos victoria! / Yo estoy en la gloria: / ¡se fue mi mujer!” (Romano 167). La imagen de la noria como figura del matrimonio, de la cual dice él haberse escapado, es muy rica en significados porque implica subordinación total, trabajo agotador en beneficio de otro (en este caso la mujer) y rutina terriblemente tediosa. Por eso, deshacerse de la esposa significa "volver a vivir”. Como en "Chorra”, el uso de vocabulario lunfardo, la exageración, incluso el ritmo marcado por la música del mismo Discépolo, como así también las imágenes creadas producen el efecto cómico. De éstas últimas la más lograda es cuando dice: “Gracias a Dios / que me salvé de andar / toda la vida atao / llevando el bacalao / de la Emulsión de Scott...!”. Como dice Eduardo Romano, "La emulsión fabricada por Scott era un tónico, preparado a base de hígado de bacalao, en cuya etiqueta un individuo cargaba pesadamente sobre sus espaldas uno de esos pescados" (167). Esta ingeniosa referencia a un producto popular de esa época no por cómica es menos brutal en lo que hace a la imagen de la mujer y a la carga que el matrimonio significa para el hombre. 
“Soy un arlequín” (1928/9) epitomiza la representación discepoliana del hombre y la mujer a través de las imágenes de Jesús y Magdalena. La voz masculina dice "Me engañó tu voz, / tu llorar de arrepentida sin perdón. / Eras mujer...pensé en mi madre, / iy me clavé!” (Romano 152). La mujer por definición, salvo la madre, claro, y ya hemos visto esta dicotomía, es una perdida y una traidora, mientras que el hombre es el que tiene la fibra moral para intentar la salvación de aquélla. Pero esta tarea, precisamente por el carácter de la mujer, está destinada al fracaso. La mujer, sin embargo, no es más que parte de la sociedad, parte fundamental por supuesto en lo que hace a relaciones básicas del individuo con los otros. Por eso la voz poética en “Tres esperanzas” (1933) dice que "Tres esperanzas tuve en mi vida, / dos eran blancas y una punzó... / Una mi madre, vieja y vencida, / otra la gente, y otra un amor. / Tres esperanzas tuve en mi vida, / dos me engañaron, y una murió” (Romano 251). La angustia de la voz discepoliana proviene justamente de enfrentar este fracaso de todas las esperanzas e ilusiones de la juventud, lo que le da "terror al porvenir”, terror de vivir en una sociedad en la que "el otro" es siempre un enemigo. La desesperación lleva a la voz poética a proponer “cachá el bufoso. . .y chau.. .vamo a dormir" (bufoso: revólver) y esta propuesta de suicidio indica dos facetas de la crisis: por un lado, la crítica de una sociedad donde impera la más profunda alienación, y por otro, la imposibilidad de visualizar un cambio. ${ }^{6}$

Este sentido de alienación y de desesperación se expresa en lo mejor y más conocido de la obra de Discépolo. En "Yira. ..yira...” (1929), por ejemplo, se hace referencia a la “indiferencia del mundo / que es sordo y es mudo" frente al dolor del individuo (Romano 210). Este tango comienza afirmando que la suerte es "grela” (mujer), no simplemente, claro, porque "suerte" sea un sustantivo femenino, sino porque podemos estar seguros que nos va a "fayar" igual que la mujer. El mismo título del tango resuena con distintos significados. En lo inmediato se refiere "al mundo" que gira y gira continuamente y "nada le importa”. Pero también se refiere al peregrinaje del hombre, que rompe "Los tamangos, / buscando ese mango / que le haga morfar" (rompe los zapatos buscando el dinero para poder comer). Y finalmente es imposible no oír también aquí el eco de otra acepción del término merced a la cual ese peregrinaje se transforma en prostitución. Esto último es importante porque relaciona directamente la alienación con la cuestión material, económica, de clase, en el contexto de la profunda crisis económica de la década infame.

Es la crisis económica también lo que está detrás de la motivación de la voz masculina en “Confesión” (1930). Esta se dirige a la mujer ausente para explicar que los maltratos que le dio fueron en realidad para salvarla. La mujer aquí no aparece como traidora; por el contrario, se ha ido obligada por el hombre. Pero el dilema de éste se expresa hacia el comienzo del tango en esta construcción oximorónica: "Hoy me odiás, / y yo feliz / me arrincono pa'yorarte” (Romano 203). La llora porque la ha perdido pero al mismo tiempo está feliz porque "la miseria cruel” que le ofreció lo justifica al verla ahora "hecha una

\footnotetext{
${ }^{6}$ Norberto Galasso llama la atención a la cantidad de suicidios en esa época y establece una relación entre este tango y esos suicidios como producto de la crisis profunda que vive el país. Basándose en las memorias policiales desde principios de siglo hasta 1955, señala que "1932 es precisamente el año en que se bate el record de suicidios en la Capital Federal, tanto en valores absolutos como en valores relativos" (86). Ver obra citada, capítulo V y apéndice "B”.
} 
reina”. Aquí vemos nuevamente la superioridad moral del hombre, que es capaz de sacrificarse por el bien de la amada aunque para salvarla, como él dice, sólo haya sabido hacerse odiar. De esta manera, este tango pretende crear simpatía hacia el hombre porque aunque el medio haya sido "horroroso", en realidad está justificado por la nobleza del fin, estrategia ésta que le permite enfatizar y criticar las condiciones sociales que le dieron origen. A pesar de esas condiciones sociales, la agencia del hombre hace que paradójicamente el amor triunfe, aunque no en la unión sino en la separación de los amantes.

El énfasis en “Confesión” como en los tangos de Discépolo que hemos visto antes y en otros posteriores está en el carácter alienante de la sociedad que impide el amor entre el hombre y la mujer y la solidaridad entre los seres humanos en general. La textualización de la desesperación y la angustia ante ese hecho llega al extremo de utilizar la estrategia sorprendente, por todo lo que hemos visto, de criticar a la madre. En el tango muy apropiadamente llamado “Desencanto” (1937), la voz poética dice pensando en su niñez: “Oigo a mi madre aún”, lo que crea una serie de expectativas basadas en la figura tradicional de la madre, para destruirlas brutalmente al agregar: "La oigo engañándome. / Porque la vida me negó / las esperanzas que en la cuna / me cantó” (Romano 278-79). La madre representa aquí no el refugio seguro al que se puede volver sino el espacio ideológico doméstico en el que se nos inculca desde niños el discurso del status quo. De esta manera, este tango cierra todas las puertas y no deja ningún resquicio por donde poder escapar.

Esta alienación que hemos visto a nivel individual y la crítica social se hacen más generales y explícitas en los que son considerados como los dos tangos más “políticos” de Discépolo. “Cambalache” (1935) se transformaría con el tiempo en el himno no oficial de los argentinos y sería debidamente prohibido por la última dictadura militar. Como señala Eduardo Romano, “como indicio de la confusión contemporánea, Discépolo menciona una serie de figuras contrastantes y de actualidad a comienzos de la década del 30” (277). Tanto la combinación de estas figuras como el conjunto del texto dejan perfectamente en claro que la crisis no es sólo de carácter local sino mundial. La mención de Alexander Stavisky es particularmente interesante en lo que hace a la relación que hubo entre la carrera delictiva de este estafador y el ascenso del fascismo en Europa, especialmente en Francia.

En la base de mi análisis hay una concepción metonímica de la familia con respecto al conjunto de la sociedad. De manera semejante, “iQué sapa, Señor!” (1931) usa la casa metafóricamente al plantear que el hombre "voltió la casa vieja/antes de construir la nueva./Creyó que era cuestión / de alzarse y nada más [...] No vio que a su pesar/no estaba preparao;/y él solo se enredó al saltar” (Romano 229). Aquí el sentido de desesperación va de la mano de la desmoralización frente al fracaso de los intentos de cambio, y éstos son vistos como falta de "preparación" del hombre en general y en abstracto, hombre al cual "lo ha mareao/el humo al incendiar./Y ahora entreverao/no sabe adónde va". De esta manera, no se ve salida y, peor aun, las experiencias revolucionarias del pasado y las luchas del momento son consideradas como parte del "caos que horroriza y espanta". Estas son las bases del discurso pesimista del poeta tanguero más “político” no sólo de esa época sino de siempre, a comienzos de una década infame no sólo para los argentinos sino para toda la humanidad; una década que había comenzado con el primer golpe militar en Argentina, 
pero que vería también el triunfo de Hitler en Alemania, el de Franco en España, el comienzo de la segunda guerra mundial y los infames juicios de Moscú.

En forma más indirecta, otros poetas de esta época apelan a la nostalgia como forma de comentar sobre un presente que se percibe caótico y alienante. Es un elemento fundamental en la obra de Homero Manzi y en mayor o menor medida también en las de Alfredo Le Pera, Enrique Cadícamo y Cátulo Castillo. Basándose en Raymond Williams en The Country and the City, Beatriz Sarlo plantea que

\begin{abstract}
El tópico de la "edad dorada” es la configuración literaria de la estructura ideológicoafectiva que emerge de las desazones causadas por lo nuevo: restituye en el plano de lo simbólico un orden que se estima más justo, aunque nunca haya existido objetivamente y sea, más bien, una respuesta al cambio antes que una memoria del pasado. Por eso la "edad dorada” no es una reconstrucción realista ni histórica, sino una pauta que, ubicada en el pasado, es básicamente acrónica y atípica: de algún modo, una utopía, en cuyo tejido se mezclan deseos, proyectos y, sin duda, también recuerdos colectivos. (32)
\end{abstract}

La comparación con un pasado supuestamente mejor sirve como estrategia para enfatizar los cambios producidos y lo que se ha perdido con el paso del tiempo. El barrio, especialmente el arrabal, donde uno nació encarna valores de unidad familiar y de solidaridad comunitaria a los que ya me he referido. En lo que es claramente un contradiscurso, estos tangos plantean que el "progreso", al destruir el barrio, ha destruido también esos valores, dejando al hombre solo y desamparado. En "Puente Alsina” (1926), de Benjamín Tagle Lara, vemos por ejemplo que "Mi barrio es mi madre que ya no responde.../¡Que digan adónde lo han ido a enterrar!” (Romano 101), donde la equiparación del barrio con la madre atribuye a aquél todas las virtudes de ésta que hemos examinado.

De alguna manera, hemos completado un círculo. Si los tangos de la década de 1910 y principios de la de 1920 prevenían sobre los peligros de abandonar el barrio, aunque esas advertencias iban dirigidas fundamentalmente a las mujeres, los tangos de 1930 en adelante presentan las consecuencias de ese abandono, ya sea por voluntad propia y/o por la destrucción del arrabal causada por el "progreso". Como diría Homero Manzi en “Sur” (1948), "Nostalgia de las cosas que han pasado,/arena que la vida se llevó,/pesadumbre de barrios que han cambiado/y amargura del sueño que murió” (Romano 382).

Para terminar, me gustaría retomar esta idea del barrio y referirme a "No salgas de tu barrio” (1927) de A.J. Rodríguez Bustamante. En este tango la voz femenina se dirige a otra mujer para exhortarle a no abandonar todos los clichés que constituyen este discurso de defensa de los valores tradicionales encarnados en el barrio: la costura, la lamparita a kerosene, la vieja, la calle, el conventillo y el "muchacho sencillote que suplica tu querer”. Como decía al principio de este trabajo, pobreza pero honrada. Por eso es que aconseja que "No salgas de tu barrio, sé buena muchachita,/casate con un hombre que sea como vos/y aun en la miseria sabrás vencer tu pena/y ya llegará un día en que te ayude Dios” (Gobello 130). De lo contrario, le pasará lo que a la voz poética, que se dejó seducir por “un niño engominado” que la convirtió en un “despojo”. Aunque sea un poco repetitivo, quería terminar replanteando este discurso para compararlo con uno de los poquísimos tangos de esta época escritos por una mujer. Se trata de “Se va la vida” (1929), escrito por Luis Mario 
que es en realidad un seudónimo para María Luisa Carnelli. De alguna manera, ya los títulos de estos tangos indican dos filosofías completamente distintas. En éste, la voz femenina también se dirige a otra mujer, pero esto es lo que le dice: "Se va la vida.../Se va y no vuelve.../Escuchá este consejo:/si un bacán te promete acomodar,/entrá derecho viejo./Pasan los días,/pasan los años,/es fugaz la alegría.../¡No pensés en dolor ni en virtud!/¡Viví tu juventud!” (Gobello, 164). Subvierte uno de los elementos tradicionales del tango, la seducción de un "bacán", al presentarlo no como amenaza sino como alternativa. De la misma manera, en "No salgas de tu barrio" la referencia a Dios indica conformismo y quietud, aceptación del rol pasivo asignado a la mujer y de las condiciones que la rodean y creencia que sólo la providencia divina puede cambiar esas circunstancias; mientras que en "Se va la vida" la negación de ese poder divino al afirmar que a la vida "ni Dios la sujeta” forma parte de un llamado imperioso a la mujer a ejercer su agencia y tomar su destino en sus manos "porque, a lo mejor,/la suerte te alcanza/si te decidís”.

Al analizar la obra de Enrique Santos Discépolo señalaba su visión de la domesticidad pequeñoburguesa y su relación con el mantenimiento del status quo y la construcción de la subjetividad, fundamentalmente masculina. Como hemos visto, los tangos escritos por hombres tienden a construir a la mujer como objeto, no como sujeto. Por el contrario, este último tango, "Se va la vida”, escrito por una mujer, hace un llamado a la construcción de una subjetividad femenina que debe necesariamente darle "un golpe de hacha" "al mismo recuerdo", es decir que debe romper radicalmente con el pasado. Pero como sugiere la última cita en el párrafo anterior, no hay garantías de éxito, sólo la posibilidad de un futuro mejor. Si este llamado nos parece tibio actualmente, debemos recordar el momento en que apareció y que lo hizo como contradiscurso frente a una cantidad innumerable de tangos que reproducían un discurso que pretendía mantener a la mujer como objeto. El simple hecho de que la autora tuviera que usar un seudónimo masculino indica su posición contradictoria en el terreno de los conflictos discursivos.

Después de estas dos décadas tan ricas, el tango comienza lentamente a declinar. Ya en 1964 Andrés Carretero afirma que "el tango ha cumplido una parábola descendente, pues del éxito indiscutido que logró en la década de 1920, ha quedado relegado a planos secundarios en la preferencia del público" (63). Este crítico trata de explicar la decadencia del tango por haber abandonado a su supuesta clase de origen, el proletariado, y haberse transformado en música de la clase media. Su decadencia iría de la mano, según él, de la decadencia de esta clase media y de la imposibilidad del tango de evolucionar al calor de las grandes transformaciones que ha sufrido la sociedad. Creo que esto último es innegable y se expresa de alguna manera en un "canon" de tangos producidos en las décadas del veinte y del treinta que, como decía al principio, todavía siguen siendo favoritos pero que no pueden responder de ninguna manera a las preocupaciones actuales y que mantendrían tan sólo un alto valor nostálgico. Precisamente hacia la época en que escribe Carretero la juventud de clase media se acerca a la música folklórica argentina y al rock y a partir de estas dos vertientes encontrará expresión en lo que daría en llamarse "la nueva canción" y el "rock nacional”. Pero ése, como dice el protagonista al final de la película Tango Bar, "ése es otro tango". Lo que me interesa enfatizar para terminar es el rol fundamental que cumplió el tango, a través de su intervención en el terreno cultural en un momento crucial de la historia argentina, en la estructuración y consolidación de la clase media porteña. 
Bibliografía

Amadeo, Tomás. La función social. Buenos Aires: El Museo Social Argentino, 1929.

Archetti, Eduardo P. Masculinities: Football, Polo and the Tango in Argentina. Oxford/ Nueva York: Berg, 1999.

Carretero, Andrés. El compadrito y el tango. Buenos Aires: Ediciones Pampa y Cielo, 1964.

Ferrer, Horacio y Luis Adolfo Sierra. Discepolín. Buenos Aires: Ediciones del Tiempo, 1965.

Galasso, Norberto. Discépolo y su época. Buenos Aires: Editorial Jorge Alvarez S.A., 1966.

Gobello, José, editor. Letras de tango. Selección (1897-1981). Buenos Aires: Ediciones Nuevo Siglo, 1995.

La historia del tango. Buenos Aires: Ediciones Corregidor, 1976.

Romano, Eduardo, editor. Las letras del tango. Antología cronológica 1900-1980. Rosario: Editorial Fundación Ross, 1994.

Sarlo, Beatriz. Una modernidad periférica: Buenos Aires 1920 y 1930. Buenos Aires: Ediciones Nueva Visión, 1988.

Ulla, Noemí. Tango rebelión y nostalgia. Buenos Aires: Editorial Jorge Alvarez S.A., 1967. 